\title{
Rheological Behavior of Agharan Contains Different Concentrations of Whey Powder, Starch and Gum Arabic
}

\section{Barat Ali ZY'** and Khomeiri $\mathbf{M}^{2}$}

${ }^{1}$ Msc of Food Science and Technology, Gorgan University of Agriculture Sciences and Natural Resources, Gorgan, Iran

${ }^{2}$ Department of Food Science and Technology, Gorgan University of Agriculture Sciences and Natural Resources, Gorgan, Iran

\begin{abstract}
The Agharan is fermented concentrated fermented camel milk which prepared in some pastoral region of Golestan Province in Iran, and among the Turkmen tribes where camels are kept and bred called Agharan. Agharan has not been introduced in any article, conferences or etc. in the world, yet. So this is the first article written about Agharan and has introduced it, and investigate the rheology of this product. Accordingly, this study can provide important information for other researchers. The aim of the this work is to study the effect of $0.05,0.1$ and $0.15 \%$ Whey Powder, Gum Arabic and Starch at 30, 40, 50, 60, 70, 80, 90, 100, 105, $120,135,140,150,160,180,200 \mathrm{rpms}$ on rheological properties of Agharan at $24^{\circ} \mathrm{C}$. Results with Mitschka Method revealed all samples were Shear Thining. All samples showed similar decrease in apparent viscosity with increasing the Shear rate. In all concentration of Agharan contain Gum arabic, viscosity decreased slightly in comparison to control. In contrast, Agharan contains $0.15 \%$ Whey powder has sharp slope. The level of decrease depended on the levels of materials added. The highest and lowest Apparent viscosity were recorded for Agharan contain 0.1, 0.05\% Starch $(3520.7,2678.4)$ and $0.15 \%$ gum arabic (823.25) respectively. Accordingly Starch, Whey powder and Gum Arabic can alter rheological properties of Agharan.
\end{abstract}

Keywords: Agharan; Fermented camel milk; Starch; Rheological behavior; Shear thinning

\section{Introduction}

Rheology is the study of deformation and flow of fluids in response to stress. To make an incompressible fluid flow, a shear stress must be applied.

Camel is a useful animal which many years ago domesticated by human and used its Milk, Meat, Skin, Wool and so one. Fermented camel milk is one of the 3500 traditional fermented food exist in the world [1], that believed to be one of the oldest fermentation products known to humans, originating in the Middle East and Africa and is consumed by some people in pastoralis regions $[2,3]$.

Camel milk and fermented camel milks are nutritious foods because has medicinal properties and in many region used against some diseases [4-7]. The Agharan is fermented concentrated camel milk which prepared in some pastoral region of Golestan Province in Iran, and among the Turkmen tribes where camels are kept and bred, called Agharan. It is prepared by gathering the thin layer of fermented camel milk and has a nutritious value and serve especially as a breakfast. It is similar to concentrated yoghurt.

Most of whey protein is lost in the drainage without any benefit [8]. The environmental pollution and high cost of disposing it, also, the high nutritional value [9], and low cost of whey encouraged scientists to utilize it as an excellent food component in the foods [10]. Functional properties of whey proteins, such as emulsifying, water/fat holding, extending shelf-life, foaming, thickening and gelling properties [11], also nutritional value [12], make them interesting to be used as a food ingredient in conjunction fermented milks [13]. Several studies have used whey powder in yoghurt making which leads to provide better consistency, texture and creaminess to the product.

Plant hydrocolloids used in foods for improve texture and stability. Gums are polysaccharides that classified according to their origin [14]. Gum Arabic, also called Acacia Gum is the natural exudate from the Acacia Senegal, which have high molecular weight consisting of branched arabinogalactan heteropolymers $[15,16]$. The gums have the ability to control the rheology and texture throughout the stabilization of emulsions, suspensions, foams and starch gelatinization [17]. Gum Arabic also contains proteins (2\%). Uranic acid in Gum Arabic is responsible for the polyanionic character of it with a $\mathrm{pH}$ around 3 $[18,19]$.

Starch is one of the most used thickeners in dairy products due to improve mouth feel, prevent syneresis and low cost when compared with other hydrocolloids [20].

The aim of the present work is to study the effect of the addition of different concentration of Whey Powder, Gum Arabic and Starch on rheological properties of Agharan.

\section{Material and Methods}

\section{Materials}

Whey powder used in this study was a commercial product from Golestan Dairy Industries Company (PEGAH, Iran) with about composition of $11 \%$ Protein, moisture 5\%, total solids $95 \%, 1.5 \%$ fat, and acidity (lactic acid) $0.12 \%$ as per manufacturer's data. Starch obtained from Merck Company, (Germany). Agharan from onehumped camel (Camelus dromedarius) purchase from Bandar Torkman city in Golestan Province (Iran). Also Gum Arabic used in this study. All the examinations carry out in the laboratory of Department of Food Science and Technology of Agricultural Science and Natural Resources University, Gorgan, Iran.

*Corresponding author: Barat ali Zarei Yam, Msc of Food Science and Technology, Gorgan University of Agriculture Sciences and Natural Resources, Gorgan, Iran Tel: +989378212956; Fax: 49138-15739; E-mail: alizarei1662@gmail.com

Received February 18, 2014; Accepted May 27, 2014; Published June 17, 2014

Citation: Barat Ali ZY, Khomeiri M (2014) Rheological Behavior of Agharan Contains Different Concentrations of Whey Powder, Starch and Gum Arabic. J Food Process Technol 5: 330. doi:10.4172/2157-7110.1000330

Copyright: (c) 2014 Barat Ali ZY, et al. This is an open-access article distributed under the terms of the Creative Commons Attribution License, which permits unrestricted use, distribution, and reproduction in any medium, provided the original author and source are credited. 
Citation: Barat Ali ZY, Khomeiri M (2014) Rheological Behavior of Agharan Contains Different Concentrations of Whey Powder, Starch and Gum Arabic. J Food Process Technol 5: 330. doi:10.4172/2157-7110.1000330

Page 2 of 6

\section{Preparation method of Agharan}

For preparation of Agharan allowe to camel milk to quiet in a steady place at ambient temperature after it break into two phases, the solids are remove gently from the thin layer of coagulated milk that partially fermented. In fact, it is concentrated sour camel milk which in Turkmen dialect in Iran called Agharan. Total solids, $\mathrm{pH}$ and acidity (Dornic) of the Agharan used in this study were $20 \%, 4.4$ and 80 , respectively.

\section{Addition of powders and mixing}

Three levels of Starch, Whey powder and Gum Arabic $(0.05,0.1$ and $0.15 \%)$ were considered in this study. Powders were added to Agharan under gentle constant mixing with aid a Kitchen mixer for 1 min. Then the samples were kept at $4-5^{\circ} \mathrm{C}$ for $24 \mathrm{~h}$ before any tests were carried out. Before using Gum arabic, first its solution was prepared by hydrating in distilled water, mixed with a magnetic stirrer for $24 \mathrm{~h}$ at $60^{\circ} \mathrm{C}$, then added to Agharan and sample kept at $4-5^{\circ} \mathrm{C}$ for $24 \mathrm{~h}$.

A control batch (without whey protein, starch and Gum Arabic) was also mixed under similar conditions.

\section{Rheological measurements}

The Apparent viscosity of the Agharan determined at $24^{\circ} \mathrm{C}$ at various Shear rates (from 9.51 to $100 \mathrm{~s}^{-1}$ ) with the aid of a Brookfield RDVD-II, viscometer (Brookfield Engineering Laboratories, USA) using spindle No 3 at different rpms $(30,40,50,60,70,80,90,100,105$, $120,135,140,150,160,180,200)$. For each sample three readings were taken and their means were reported.
The sample was placed in a $600 \mathrm{~mL}$ low form Griffin beaker and a disc was inserted into the sample. To eliminate any time-dependent behavior, sample was subjected to pre-shearing until a constant torque was observed. Formal data collection of torque at various rotational speeds followed immediately. All data were collected at room temperature, approximately $24^{\circ} \mathrm{C}$.

Mitschka method [21] tested with spindle No 3. Values of $a_{i}$ (on the torque dial from units $0-100$ ) are converted to the (average) Shear stresses $\tau_{i}$ (in pa) on spindle used by

$$
\tau_{\mathrm{i}}=\mathrm{k}_{\text {at }} \mathrm{a}_{\mathrm{i}}
$$

Pairs of $\tau_{\mathrm{i}}-\mathrm{N}_{\mathrm{i}}$ (rotational speed in rpm) valid for spindle are plotted in the $\log -\log$ form.

When this dependence is sufficiently close to a linear one, the fluid under test is of the power -law type. The slope of the $\log \tau_{i}-\log N$ dependence in this case is equal to the flow index of the fluid or $n$.

Using values of $\mathrm{k}_{\mathrm{ny}}(\mathrm{n})$ for this flow index and spindle number, the corresponding values of the Shear rates $\mathrm{y}_{\mathrm{i}}\left(\right.$ in s $\left.^{-1}\right)$ are then calculated as

$$
\mathrm{y}_{\mathrm{i}}=\mathrm{k}_{\mathrm{ny}}(\mathrm{n}) \mathrm{N}_{\mathrm{i}}
$$

The relevant pairs $\tau_{i-} y_{i}$ are assumed to be the points of the viscosity function of the fluid sample tested. Conversion factor for the method

\begin{tabular}{|c|c|c|c|c|c|c|c|c|}
\hline \multicolumn{2}{|c|}{ Spindle number } & 1 & 2 & 3 & 4 & 5 & 6 & 7 \\
\hline \multicolumn{2}{|c|}{$\mathbf{k}_{\text {at }}$} & 0.035 & 0.119 & 0.279 & 0.539 & 1.05 & 2.35 & 8.4 \\
\hline \multirow{10}{*}{$k_{n y}$} & $\mathrm{n}=0.1$ & 1.728 & 1.431 & 1.457 & 1.492 & 1.544 & 1.366 & 1.936 \\
\hline & 0.2 & 0.967 & 0.875 & 0.882 & 0.892 & 0.907 & 0.851 & 1.007 \\
\hline & 0.3 & 0.705 & 0.656 & 0.656 & 0.658 & 0.663 & 0.629 & 0.681 \\
\hline & 0.4 & 0.576 & 0.535 & 0.530 & 0.529 & 0.528 & 0.503 & 0.515 \\
\hline & 0.5 & 0.499 & 0.458 & 0.449 & 0.445 & 0.442 & 0.421 & 0.413 \\
\hline & 0.6 & 0.449 & 0.404 & 0.392 & 0.387 & 0.382 & 0.363 & 0.346 \\
\hline & 0.7 & 0.414 & 0.365 & 0.350 & 0.343 & 0.338 & 0.320 & 0.297 \\
\hline & 0.8 & 0.387 & 0.334 & 0.317 & 0.310 & 0.304 & 0.286 & 0.261 \\
\hline & 0.9 & 0.367 & 0.310 & 0.291 & 0.283 & 0.276 & 0.260 & 0.232 \\
\hline & 1 & 0.351 & 0.291 & 0.270 & 0.262 & 0.254 & 0.238 & 0.209 \\
\hline
\end{tabular}
described by mitschka show in Table 1 .

Table 1: Conversion factor for the spindles of the Brookfield R.V.T. viscometer (under standard measuring conditions).

\begin{tabular}{|c|c|c|}
\hline & Agharan without additives & Apparent viscosity ( pa. s) \\
\hline Shear stress (pa) & Shear rate $\left(\mathbf{s}^{-1}\right)$ & 2053.6 \\
\hline 19530 & 9.51 & 1571 \\
\hline 19920.6 & 12.68 & 1577.2 \\
\hline 24998.4 & 15.85 & 1550.5 \\
\hline 33780.3 & 19.02 & 1522.6 \\
\hline 37888.2 & 22.19 & 1494 \\
\hline 41989.5 & 25.36 & 1441.7 \\
\hline 45700.2 & 28.53 & 1441.64 \\
\hline 52535.7 & 31.7 & 1425.8 \\
\hline 57222.9 & 33.285 & 1381 \\
\hline 57808.8 & 38.04 & 1505.8 \\
\hline 61910.1 & 42.795 & 1302.59 \\
\hline 73432.8 & 44.38 & 1302 \\
\hline 80463.6 & 47.55 & 1305.33 \\
\hline
\end{tabular}

$\mathrm{Pa}=$ pascal, pa.s=pascal second 
Citation: Barat Ali ZY, Khomeiri M (2014) Rheological Behavior of Agharan Contains Different Concentrations of Whey Powder, Starch and Gum Arabic. J Food Process Technol 5: 330. doi:10.4172/2157-7110.1000330

Page 3 of 6

\begin{tabular}{|c|c|c|c|c|c|c|c|c|}
\hline \multicolumn{3}{|c|}{ Agharan contains $0.05 \%$ Starch } & \multicolumn{3}{|c|}{ Agharan contains $0.1 \%$ Starch } & \multicolumn{3}{|c|}{ Agharan contains $0.15 \%$ Starch } \\
\hline Ss (pa) & $\operatorname{Sr}\left(s^{-1}\right)$ & A.vis (pa.s) & Ss (pa) & $\operatorname{Sr}\left(s^{-1}\right)$ & A.vis (pa.s) & Ss (pa) & $\operatorname{Sr}\left(s^{-1}\right)$ & A.vis (pa.s) \\
\hline 28123.2 & 10.5 & 2678.4 & 51754.5 & 14.7 & 3520.7 & 20311.2 & 9.51 & 2135.77 \\
\hline 36130.5 & 14 & 2580.75 & 58394.7 & 19.6 & 2979.3 & 21873.6 & 12.68 & 1725 \\
\hline 43161.3 & 17.5 & 2466.36 & 64058.4 & 24.5 & 2614.62 & 27732.6 & 15.85 & 1749.7 \\
\hline 49410.9 & 21 & 2352.9 & 69331.5 & 29.4 & 2358.2 & 32810.4 & 19.02 & 1762.8 \\
\hline 55269.9 & 24.5 & 2255.9 & 74018.7 & 34.3 & 2157.98 & 37497.6 & 22.19 & 1689.84 \\
\hline 60738.3 & 28 & 2169.22 & 78510.6 & 39.2 & 2002.82 & 41989.5 & 25.36 & 1655.74 \\
\hline 66011.4 & 31.5 & 2095.6 & 83197.8 & 44.1 & 1886.57 & 46286.1 & 28.53 & 1622.36 \\
\hline 71089.2 & 35 & 2031.12 & 87299.1 & 49 & 1781.6 & 50387.4 & 31.7 & 1589.5 \\
\hline 73432.8 & 36.75 & 1998.17 & 89838 & 51.45 & 1746.12 & 52340.4 & 33.285 & 1572.49 \\
\hline 80268.3 & 42 & 1911.15 & 92767.5 & 58.8 & 1577.68 & 58004.1 & 38.04 & 1524.8 \\
\hline 86322.6 & 47.25 & 1826.93 & 98821.8 & 66.15 & 1493.9 & 60543 & 42.795 & 1414.72 \\
\hline 88080.3 & 49 & 1797.56 & 99993.6 & 68.6 & 1457.6 & 63081.9 & 44.38 & 1421.4 \\
\hline 90814.5 & 52.5 & 1729.8 & 102141.9 & 73.5 & 1389.68 & 66402 & 47.55 & 1396.46 \\
\hline 93744 & 56 & 1674 & 105657.3 & 78.4 & 1347.67 & 71870.4 & 50.72 & 1417 \\
\hline 103313.7 & 63 & 1639.9 & 115227 & 88.2 & 1306.42 & 79682.4 & 57.06 & 1396.47 \\
\hline 112492.8 & 70 & 1607 & 123234.3 & 98 & 1257.49 & 87103.8 & 63.4 & 1373.88 \\
\hline
\end{tabular}

Ss=shear stress, $\mathrm{Sr}=$ shear rate, $\mathrm{A}$. vis=Apparent viscosity, $\mathrm{Pa}=$ pascal, pa.s=pascal. second

Table 3: Agharan with different concentration of Starch.

\begin{tabular}{|c|c|c|c|c|c|c|c|c|}
\hline \multicolumn{3}{|c|}{ Agharan contains $0.05 \%$ Gum arabic } & \multicolumn{3}{|c|}{ Agharan contains $0.1 \%$ Gum arabic } & \multicolumn{3}{|c|}{ Agharan contains $0.15 \%$ Gum arabic } \\
\hline Ss (pa) & $\operatorname{Sr}\left(s^{-1}\right)$ & A.vis (pa.s) & Ss (pa) & $\operatorname{Sr}\left(\mathbf{s}^{-1}\right)$ & A.vis (pa.s) & Ss (pa) & $\operatorname{Sr}\left(\mathbf{s}^{-1}\right)$ & A.vis (pa.s) \\
\hline 36130.5 & 13.8 & 2618.15 & 34177.5 & 14.4 & 2373.43 & 34177.5 & 15 & 2278.5 \\
\hline 40622.4 & 18.4 & 2207.74 & 38474.1 & 19.2 & 2003.86 & 38474.1 & 20 & 1923.7 \\
\hline 44723.7 & 23 & 1944.5 & 42380.1 & 24 & 1765.84 & 42380.1 & 25 & 1695.2 \\
\hline 48434.4 & 27.6 & 1754.87 & 45895.5 & 28.8 & 1593.6 & 46090.8 & 30 & 1536.36 \\
\hline 52145.1 & 32.2 & 1619.4 & 49410.9 & 33.6 & 1470.56 & 49215.6 & 35 & 1406.16 \\
\hline 55660.5 & 36.8 & 1512.51 & 52926.3 & 38.4 & 1378.29 & 52731 & 40 & 1318.27 \\
\hline 59175.9 & 41.4 & 1429.37 & 56051.1 & 43.2 & 1297.47 & 55660.5 & 45 & 1236.9 \\
\hline 62300.7 & 46 & 1354.36 & 58980.6 & 48 & 1228.76 & 58394.7 & 50 & 1167.9 \\
\hline 63667.8 & 48.3 & 1318.17 & 60347.7 & 50.4 & 1197.37 & 59761.8 & 52.5 & 1138.32 \\
\hline 68159.7 & 55.2 & 1234.77 & 64449 & 57.6 & 1118.9 & 63277.2 & 60 & 1054.62 \\
\hline 71479.8 & 62.1 & 1151 & 67769.1 & 64.8 & 1045.82 & 66402 & 67.5 & 983.73 \\
\hline 72261 & 64.4 & 1122 & 68745.6 & 67.2 & 1023 & 67378.5 & 70 & 962.55 \\
\hline 76167 & 69 & 1103.87 & 72261 & 72 & 1003.62 & 71089.2 & 75 & 947.85 \\
\hline 79096.5 & 73.6 & 1074.68 & 75190.5 & 76.8 & 979 & 74018.7 & 80 & 825.23 \\
\hline 85346.1 & 82.8 & 1030.75 & 80854.2 & 86.4 & 935.81 & 79487.1 & 90 & 883.19 \\
\hline 91205.1 & 92 & 991.36 & 86517.9 & 96 & 901.228 & 84955.5 & 100 & 895.55 \\
\hline
\end{tabular}

Ss=shear stress, $\mathrm{Sr}=$ shear rate, $\mathrm{A}$. vis=Apparent viscosity, $\mathrm{Pa}=$ pascal, pa.s=pascal. Second

Table 4: Agharan with different concentration of Gum Arabic.

\section{Statistical analysis}

The effects of concentration, N, and Shear rate on the Apparent viscosity were studied. Related graphs and curves drown by Excel. A significance level of 0.05 was utilized for all analyses.

\section{Results and Discussion}

\section{Viscosity measurements}

After calculating the Shear rate, Shear stress and Apparent viscosity (Tables 2-5), established the related curves. The Apparent viscosity of Agharan samples decreased with increase shear rate, indicating a nonNewtonian fluid and showed shear-thinning behavior (Figures 1-3) that characterized by flow behavior index values of less than 1 .

The consistency index (K) was greatest for Agharan contains starch $0.1 \%$, Gum arabic $0.05 \%$ and whey $0.1 \%$ and calculated $4.0548,3.83$ and 3.6845 respectively, and for Agharan without additives was 3.0633. The flow behavior index was highest for Agharan contains $0.15 \%$ whey, $0.1 \%$ Gum Arabic and $0.15 \%$ starch and calculated 0.812, 0.4851 and 0.7952 respectively in comparison to Agharan without additives (0.7961). All samples showed rather similar flow curves except Agharan contains $0.15 \%$ whey powder that had sharp slope. In general, all samples showed the decrease in apparent viscosity with increasing the shear rate and in all concentration of Agharan contain Gum Arabic, apparent viscosity decreased slightly in comparison to control and has mild slope (Figures 1-3).

\section{Effect of concentration on viscosity}

Figures 4, 5 and 6 show the influence of concentration on Shear stress versus Shear rate at constant temperature. The Apparent viscosity analysis of the samples revealed a significant decrease in apparent viscosity values for samples containing $0.05 \%$ Whey powder, but a higher value seen in higher concentration of Whey powder. The results suggested that rheological parameter values in the Agharan contains whey powder depended on whey concentration when present at low concentration because the whey proteins were not able to gel [22].

In all samples with increasing Shear rate, decreased the Shear 
Citation: Barat Ali ZY, Khomeiri M (2014) Rheological Behavior of Agharan Contains Different Concentrations of Whey Powder, Starch and Gum Arabic. J Food Process Technol 5: 330. doi:10.4172/2157-7110.1000330

Page 4 of 6

\begin{tabular}{|c|c|c|c|c|c|c|c|c|}
\hline \multicolumn{3}{|c|}{ Agharan contains $0.05 \%$ whey powder } & \multicolumn{3}{|c|}{ Agharan contains $0.1 \%$ whey powder } & \multicolumn{3}{|c|}{ Agharan contains $0.15 \%$ whey powder } \\
\hline Ss (pa) & $\operatorname{Sr}\left(s^{-1}\right)$ & A.vis (pa.s) & Ss (pa) & $\operatorname{Sr}\left(\mathbf{s}^{-1}\right)$ & A.vis (pa.s) & Ss (pa) & $\operatorname{Sr}\left(\mathbf{s}^{-1}\right)$ & A. vis (pa.s) \\
\hline 19725.3 & 10.5 & 1878.6 & 30662.1 & 12.6 & 2433.5 & 20311.2 & 9.51 & 2135.77 \\
\hline 20506.5 & 14 & 1464.75 & 35154 & 16.8 & 2092.5 & 28513.8 & 12.68 & 2248.72 \\
\hline 21092.4 & 17.5 & 1205.28 & 39255.3 & 21 & 1869.3 & 34958.7 & 15.85 & 2205.6 \\
\hline 22068.9 & 21 & 1050.9 & 42770.7 & 25.2 & 1697.25 & 40817.7 & 19.02 & 2146 \\
\hline 26170.2 & 24.5 & 1068.17 & 46286.1 & 29.4 & 1574.35 & 47067.3 & 22.19 & 2121.1 \\
\hline 30076.2 & 28 & 1074.15 & 49801.5 & 33.6 & 1482.18 & 52340.4 & 25.36 & 2063.9 \\
\hline 33591.6 & 31.5 & 1066.4 & 52926.3 & 37.8 & 1400.16 & 57222.9 & 28.53 & 2005.7 \\
\hline 37107 & 35 & 1060.2 & 55855.8 & 42 & 1329.9 & 62105.4 & 31.7 & 1959.16 \\
\hline 40427.1 & 36.75 & 1100 & 57222.9 & 44.1 & 1297.57 & 64253.7 & 33.285 & 1930.41 \\
\hline 41598.9 & 42 & 990.45 & 60738.3 & 50.4 & 1205.125 & 71089.2 & 38.04 & 1868.8 \\
\hline 45114.3 & 47.25 & 954.8 & 65620.8 & 56.7 & 1157.33 & 76948.2 & 42.795 & 1798.85 \\
\hline 49996.8 & 49 & 1020.34 & 67378.5 & 58.8 & 1145.9 & 78510.6 & 44.38 & 1769 \\
\hline 52145.1 & 52.5 & 993.24 & 70503.3 & 63 & 1119.1 & 82221.3 & 47.55 & 1729.15 \\
\hline 55465.2 & 56 & 990.45 & 73432.8 & 67.2 & 1092.75 & 85541.4 & 50.72 & 1686.54 \\
\hline 58590 & 63 & 930 & 79487.1 & 75.6 & 1051.41 & 91986.3 & 57.06 & 1612.1 \\
\hline 64839.6 & 70 & 926.28 & 85736.7 & 84 & 1020.67 & 101556 & 63.4 & 1601.83 \\
\hline
\end{tabular}

Ss=shear stress, $\mathrm{Sr}=$ shear rate, $\mathrm{A}$. vis=Apparent viscosity, $\mathrm{Pa}=$ pascal, pa.s=pascal. Second

Table 5: Agharan with different concentration of Whey powder.

The highest viscosity values were recorded for Agharan contains 0.1, 0.05\% Starch, were 3520.7, 2678.4, and lowest for Agharan contains $0.15 \%$ Gum Arabic (823.25). Representative plots for Shear stress versus Shear rate is shown in Figures 4, 5 and 6.

Whey proteins at low concentration do not influence significantly on rheological properties and at high Starch concentrations, it was possible to produce a hard firm structure. The presence of Gum Arabic, Starch especially Whey powder at low concentrations led to weaker structure. Similar effects of Starch addition on the properties of stirred yoghurts have been reported by Williams [23]. Also In the previous study noticed a similar tendency [22].

\section{Effect of non-viscosity values}

Agharan had Shear thining behavior and as expected in all samples apparent viscosity decreased gradually with increase in RPM, probably due to the disruption of the Agharan structure. Figures 7, 8 and 9 show the influence of RPM on Apparent viscosity of Agharan. As showed in figures, addition of whey powder, starch and Gum arabic to the Agharan resulted in a depression of apparent viscosity. All samples showed Shear thining behavior, as apparent viscosity decreased gradually when samples were subjected to shear rate. The Apparent viscosity showed a decrease with increasing Shear rate at all concentration ranges. The effect of the gelation process on the rheological properties of yogurt prepared from sheep, goat, cow and camel milks was investigated by Jumah et al. [24]. They found that the highest value for viscosity was earned by sheep milk, followed by goat, cow and camel milks. Three different transient viscosity stages were identified for cow, sheep and goat milk, whereas camel milk showed no significant variation in viscosity during gelation. The ratio of casein and whey protein in cow, sheep and goat milks are almost $80: 20$, and for camel milk is about 70 : 30 , this ratio seems have effect on viscosity and rheology properties of products made from cow, sheep, goat and camel milks. And differences in viscosity and rheology properties of these products can be attributed to the different nature of these milks.

After the aggregation/gelation of the whey proteins, rearrangements of the gel network are observed $[25,26]$, and may be due to aggregation of casein particles at iso-electric $\mathrm{pH}(\mathrm{pH} 4.6)$. Such rearrangements lead to a transition from an initial denatured whey protein (associated with 
Citation: Barat Ali ZY, Khomeiri M (2014) Rheological Behavior of Agharan Contains Different Concentrations of Whey Powder, Starch and Gum Arabic. J Food Process Technol 5: 330. doi:10.4172/2157-7110.1000330

Page 5 of 6

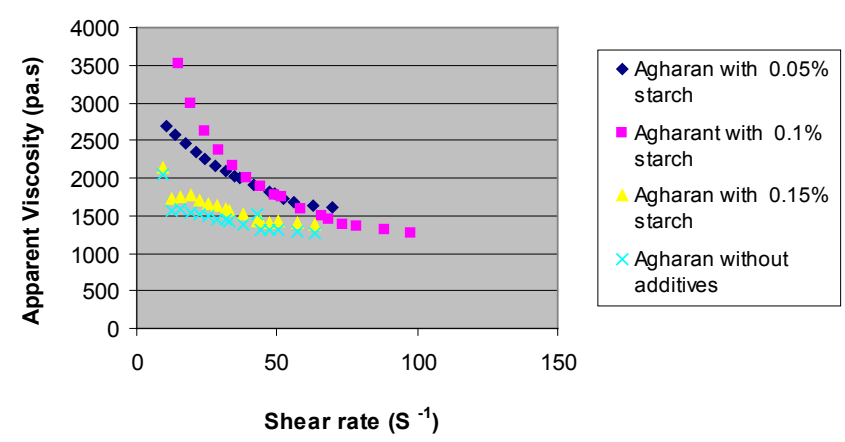

Figure 3: Apparent viscosity versus Shrear rate for Agharan contains different concentration of Starch.

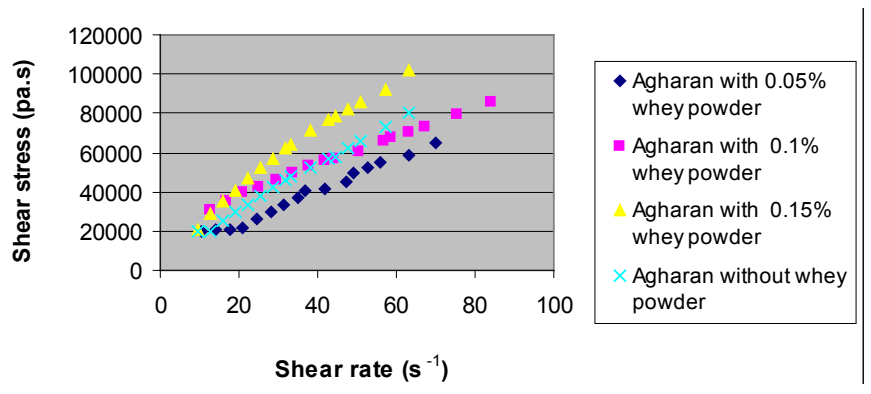

Figure 4: Shear stress versus Shear rate for Agharan contains different concentration of Whey powder.

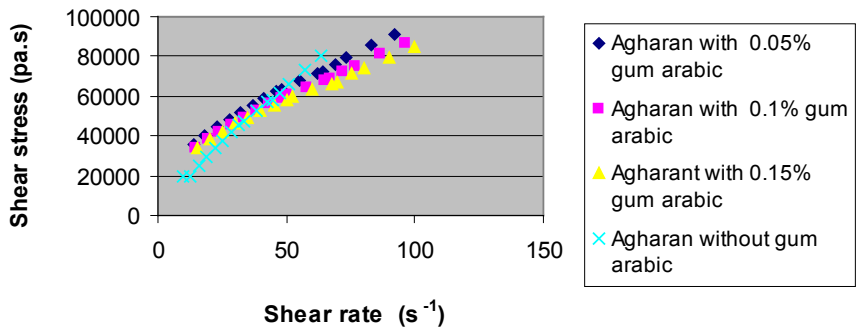

Figure 5: Shear stress versus Shear rate for Agharan contains different concentration of Gum Arabic.

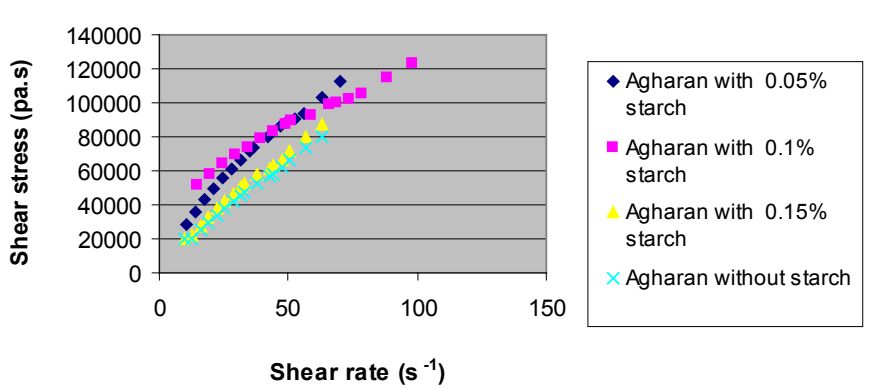

Figure 6: Shear stress versus Shear rate for Agharan contains different concentration of Starch.

casein micelles) induced gel formed at a high $\mathrm{pH}(\mathrm{pH}$ 5.2) to a network dominated by casein-casein interaction at a lower $\mathrm{pH}(\mathrm{pH}$ 4.6) [27].
Adding 6\% whey protein is sufficient to form stable three dimensional structures and reveals higher rheological parameters values. It can be due to change in the flow characteristic in the samples that arose from structural formation, while in lower whey protein concentrations, the addition of whey powder produced a marginal decrease in viscosity of system typical for shear thining behavior, without contributing to the formation of intermolecular bonds [28].

The concentration dependence of the Apparent viscosity on Shear rate, described by other researchers for Whey protein, Starch and Gum Arabic systems, was confirmed by this study also for undenatured Whey proteins $[23,22,28]$.

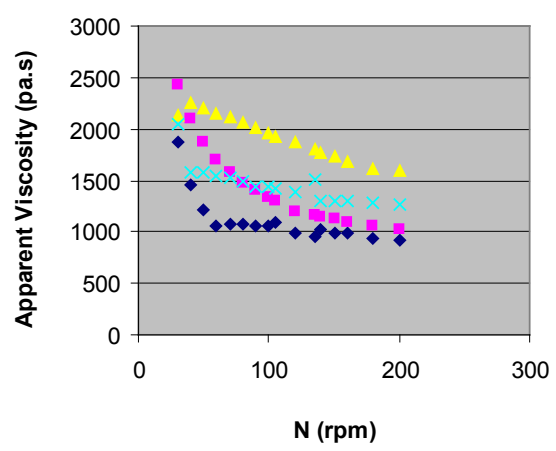

- Agharan with $0.05 \%$ whey
powder
- Agharan with $0.1 \%$ whey
powder
Agharan with $0.15 \%$ whey
powder
$\times$ Agharan without additives

Figure 7: Apparent viscosity versus $\mathrm{N}$ for different concentration of Aaghran contains Whey powder.

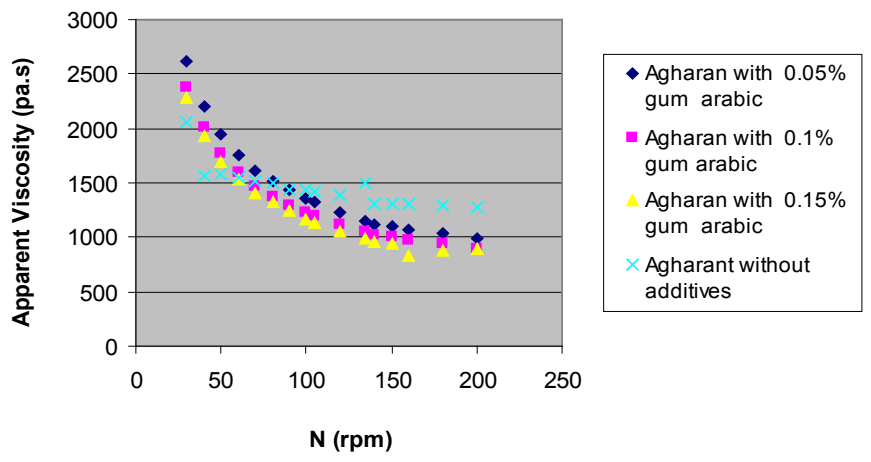

Figure 8: Apparent viscosity versus $\mathrm{N}$ for different concentration of Agharan contains Gum Arabic.

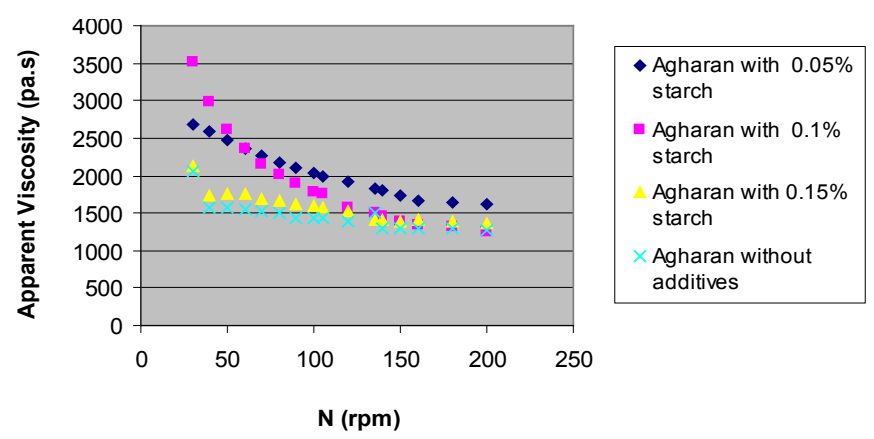

Figure 9: Apparent viscosity versus $\mathrm{N}$ for different concentration of Agharan contains Starch. 
Citation: Barat Ali ZY, Khomeiri M (2014) Rheological Behavior of Agharan Contains Different Concentrations of Whey Powder, Starch and Gum Arabic. J Food Process Technol 5: 330. doi:10.4172/2157-7110.1000330

Page 6 of 6

Near neutral $\mathrm{pH}$, whey proteins gels can be formed either by heatinduced gelation in which it is necessary to heat whey proteins in the presence of ions, or by cold- or ion-induced gelation in which the whey proteins form a three-dimensional network by aggregation. In the latter case, it is prerequisite to unfold the whey protein monomers by prior heating to expose sulfhydryl and hydrophobic amino acid residues that are buried in the interior of the globules. The unfolded proteins form polymers mainly via sulfhydryl/disulfide interactions and also via hydrophobic interactions [29]. Same reasons exist for formation of firm structure by starch and Gum arabic but with slight different in regard with they are hydrocolloids. Same results approached in this study and these hydrocolloids and whey powder decreased the apparent viscosity.

A rapid breakdown of the structure occurs on initial shearing followed by much slower changes at higher shear rates. This behavior can be attributed to combined effects of breakdown of weak linkages between the proteins and/or between the proteins and stabilizer, and of reformation of such linkages as a result of Brownian motion and molecular collisions [30].

\section{Conclusions}

The Mitschka method produces very useful information for quality control a variety of shear-thinning fluid foods. The present work has shown that addition Starch, Whey powder and Gum Arabic decrease the Apparent viscosity. The level of decrease was dependent on the level of adding.

The amount of Whey powder, Starch and Gum arabic affected the rheological and textural attributes of the Agharan. All Agharan samples in this study were Shear Thinning. Accordingly, we concluded that use of Whey powder, Starch and Gum arabic in the manufacture of Agharan can improve its physical properties.

\section{Acknowledgement}

The authors wish to thank engineer Rahil Rezaei and dr Seid Mahdi Jafari for his critical helps and valuable suggestions.

\section{References}

1. Anon It's a tiny world (online) (2003) Food Today; European Food information council online.

2. Chandan RC (2006) Manufacturing of yoghurt and fermented milks. ( $1^{\text {st }}$ edition). Blackwell Publishing Professional, Ames, lowa.

3. Tamime AY, Robinson RK (1999) Yoghurt: Science and Technology. (2 $2^{\text {nd }}$ edition). CRC Press, New York, NY.

4. Rao MB, Gupta RC, Dastur NN (1970) Camels' milk and milk products. Ind J Dairy Sci 23: 71-78.

5. Akhundov AA, Dyrdyev B, Serebryakov ER (1972) Effect of combined treatment on water electrolyte exchange in pulmonary TBC patients. Zdravookhr. Turkm 16: 40-44.

6. Sharmanov TSh, Kadyrova RKh, Shylgina OE, Zhaksylykova RD (1978) [Dynamics of the indices of radioisotope liver study methods under the influence of chronic hepatitis treatment with whole camel's and mare's milk]. Vopr Pitan : 9-13.

7. Gast M, Mauboisj L, Adda J (1969) Le lait et les produits laitiers en Ahaggar. Centre Rech Anthr Prehist Ethn.

8. Morr CV, Foegeding EA (1990) Composition and functionality of commercial whey and milk protein concentrates and isolates: A status report. Food Technology 44: 100-112.

9. Damodoran S (1996) Amino acids, peptides and proteins. Food Chemistry (3r edition). Marcel Dekker, NY.

10. Dickinson E (1997) Properties of emulsions stabilized with milk proteins: overview of some recent developments. Journal of Dairy Science 80: 26072619.
11. Hall GM, Iglesias O (1997) Functional properties of drink milk whey. Food Sci Technol Int 3: 381-383.

12. Tipton KD, Elliott TA, Cree MG, Wolf SE, Sanford AP, et al. (2004) Ingestion of casein and whey proteins result in muscle anabolism after resistance exercise. Med Sci Sports Exerc 36: 2073-2081.

13. Huffmann M (1996) Processing whey protein for use as a food ingredient. Food Technol 50: 49-52.

14. Igoe RS (1982) Hydrocolloids interactions useful in food system. Food Technology 4: 72-74.

15. Anderson DMW, Bridgeman MME, Farquhar JGK, McNab CGA (1983) The chemical characterization of the test article in toxicological studies of gum arabic (Acacia Senegal (L.) Willd). Int. Tree Crops J 2: 245-254.

16. Street CA, Anderson DM (1983) Refinement of structures previously proposed for gum arabic and other acacia gum exudates. Talanta 30: 887-893.

17. Rosell CM, Rojas JA, Bendito de barber C (2001) Influence of hydrocolloids on dough and bread quality. Food Hydrocolloids 15: 75-81.

18. Kravtchenko TP (1997) Application of acacia gum as a natural source of soluble dietary fibre. Pages 56-60 in Food Ingredient Europe, conference Proceeding. Miller Freeman, Maaersen, The Netherlands.

19. Mitschka P (1982) Simple conversion of Brookfield R.V.T. reading into viscosity functions. Rheologica Acta 21: 207-209.

20. Foss JW (2000) How processing affects starch selection for yogurt. Nationa starch and chemical company.

21. Mitschka P (1982) Simple conversion of Brookfield R.V.T. reading into viscosity functions. Rheologica Acta 21: 207-209.

22. Glibowski P, Mleko S, Wasko A, Kristinsson HG (2006) Effect of two stage heating on $\mathrm{Na}+-$ induced gelation of whey protein isolate, Milchwissenschaft 61 : 252-255.

23. Williams RPW, Glagovskaia O, Augustin MA (2003) Properties of stired yoghurts with added starch: Effect of alteration in fermentation conditions. Australian Journal of Dairy Science and Technology 58: 228-232.

24. Jumah RY, Shaker RR, Abu- Jdayil B (2001) Effect of milk source on the rheological properties of yoghurt during the gelation process. Int $\mathrm{J}$ Dairy Technol 54: 89-93.

25. Lucey JA, Munro PA, Singh H (1998a) Whey separation in acid skim milk gels made with glucono-delta-lactone: Effects of heat treatment and gelation temperature. Journal of Texture Studies 29: 413-426.

26. Lucey JA, Tamehana M, Singh H, Munro PA (2000) Rheological properties of milk gels formed by a combination of rennet and glucono-delta-lactone. J Dairy Res 67: 415-427.

27. Lucey JA, Singh H (1998b) Formation and physical properties of acid milk gels: A review. Food Research International 30: 529-542.

28. Alizadehfard MR, Wiley DE (1996) Non- Newtonian behaviour of whey protein solutions. Journal of Dairy Research 63: 315-320.

29. Vardhanabhuti B, Foegeding EA (1999) Rheological properties and characterization of polymerized whey protein isolates. J Agric Food Chem 47: 3649-3655.

30. Tang Q, Munro PA, McCarthy OJ (1993) Rheology of whey protein concentrate solutions as a function of concentration, temperature, $\mathrm{pH}$ and salt concentration. Journal of Dairy Research 60: 349-361. 